\title{
"Empregos verdes" na região do Pantanal brasileiro
}

Green jobs in the Brazilian Pantanal region

Raul Asseff Castelão ${ }^{a}$

Celso Correia de Souzab

Daniel Massen Frainer ${ }^{c}$

José Francisco dos Reis Neto ${ }^{d}$

${ }^{a}$ Doutorando em Meio Ambiente e Desenvolvimento Regional, Universidade Anhanguera Uniderp, Campo Grande, MS, Brasil. End. Eletrônico: raulassefcastelao@gmail.com

${ }^{b}$ Professor do Programa de Especialização em Meio Ambiente e Desenvolvimento Regional, Universidade Anhanguera Uniderp, Campo Grande, MS, Brasil. End. Eletrônico: csouza939@gmail.com

'Professor pesquisador da Universidade Estadual de Mato Grosso do Sul, UEMS, Campo Grande, MS, Brasil. End. Eletrônico: danielfrainer@gmail.com

${ }^{d}$ Professor do Programa de Especialização em Meio Ambiente e Desenvolvimento Regional, Universidade Anhanguera Uniderp, Campo Grande, MS, Brasil. End. Eletrônico: jfreisneto@terra.com.br

doi:10.18472/SustDeb.v8n3.2017.24352

Recebido em 03.02.2017

Aceito em 08.09.2017

ARTIGO - VARIA

\section{RESUMO}

A região do Pantanal, considerado patrimônio natural mundial e reserva da biosfera pela Unesco possui, ao mesmo tempo, o desenvolvimento de diversas atividades que podem proteger e agredir o meio ambiente. Nesse contexto, a preocupação em se ter o desenvolvimento dessas atividades de forma equilibrada com o meio ambiente tem sido uma constante para a região. Uma das ferramentas para que isso possa ocorrer é o emprego da economia verde. Neste artigo, mensuramos os "empregos verdes" na região do Pantanal entre os anos de 2002 a 2015, a partir dos dados da Relação Anual de Informações Sociais - Rais do Ministério do Trabalho. Identificamos que o número de "empregos verdes" na região do Pantanal diminuiu entre os anos de 2002 a 2015. Contudo, existe uma esperança de melhorias, pois o número de empregos com tendência de proteção ao meio ambiente cresceu no mesmo período.

Palavras-chave: Desenvolvimento sustentável. Economia verde. Economia do meio ambiente. Pantanal. 


\section{ABSTRACT}

The Pantanal wetlands region, considered as a world natural heritage and biosphere reserve by UNESCO, has simultaneously, activities that can protect and attack the environment. In this context, the concern to develop these activities in balance with the environment has been a constant concern for the region. One of the tools for this to happen is the use of the green economy. In this article, we measure green jobs in the Pantanal region between the years 2002 and 2015, based on data from the RAIS of the Ministry of Labor. We identified that the number of green jobs in the Pantanal region has declined between 2002 and 2015. However, there is hope for improvement as the number of jobs tending to protect the environment grew over the same period.

Keywords: Sustainable Development; Green economy; Economy of the Environment; Wetlands.

\section{INTRODUÇÃO}

Um tema que tem estado no cerne dos debates de políticas públicas é a questão do meio ambiente, tanto como provedor de insumo como também receptor de descartes dos produtos rejeitados e dos despejos de gases poluentes na atmosfera, derivados do processo de produção. Nesse sentido, tem-se aumentado a preocupação com o meio ambiente em função de seu reconhecimento como peça central para que as futuras gerações possam usufruir de condições favoráveis de sobrevivência no planeta, em se tratando de bem-estar social, econômico e ambiental, essencial à sadia qualidade de vida.

A corrida em prol do crescimento econômico das últimas décadas tem levado à depauperação dos recursos, à degradação e, até mesmo, à destruição do meio ambiente (DELAZARO; BARBIERI, 1994).

Desse modo, o surgimento dessa preocupação com o meio ambiente remonta à década de 1970 , quando a Organização das Nações Unidas (ONU) realizou sua Conferência Internacional em Estocolmo na Suécia, em 1972, com um olhar mais atento para as questões ambientais. Como sendo um dos frutos desse encontro, o Comitê de Brundtland, em 1984, conceituou o termo desenvolvimento sustentável, que é aquele desenvolvimento que atende às necessidades das gerações atuais sem comprometer a capacidade das gerações futuras de atenderem às suas necessidades e aspirações (ONU, 1987).

A Organização para a Cooperação e Desenvolvimento Econômico (OCDE) ressalta, a partir da compreensão da definição de desenvolvimento sustentável, que se a humanidade quiser assegurar os avanços conquistados ao longo dos últimos 50 anos nas melhorias do nível de vida, é necessário encontrar novas formas de produzir e consumir, inclusive, redefinir o conceito de medição do progresso (OCDE, 2011).

Como sendo uma possibilidade para que as nações, estados e municípios possam operacionalizar essa mudança na forma de ver, consumir e produzir tem-se o surgimento do conceito de economia verde. Esse conceito é relativamente recente e é empregado para retificar a forma como os recursos naturais são utilizados para produzir e satisfazerem a população (CEPAL, 2012).

A ideia de uma economia verde foi mencionada pela primeira vez em 1989, no estudo Blueprint for a Green Economy de Perce et al. (1989) (O'RYAN; SCHAPER, 2017). Contudo, esse conceito entrou em uso a partir da conferência da ONU Rio+20 em 2012 e, desde então, tem havido crescente interesse na relação entre economia, meio ambiente e nosso futuro comum. A economia verde desempenha nos dias atuais um papel crítico no cumprimento da Agenda 2030 para o desenvolvimento sustentável, bem como para o Acordo de Paris sobre mudanças climáticas. Nesse contexto, a economia verde é um campo interdisciplinar focado em questões de sustentabilidade de desenvolvimento, que surgiram em resposta às dificuldades na solução dos problemas ambientais no âmbito global e local (SHMELEV, 2017). 
Economia verde é aquela economia que resulta em melhoria do bem-estar da humanidade e igualdade social, ao mesmo tempo em que reduz de forma significativa os riscos ambientais e escassez ecológica (PNUMA, 2011). Para tal, é preciso reverter o cenário corrente de crescimento predatório, caracterizado pelo uso abusivo de combustíveis fósseis e outros recursos naturais e pela falta de atenção a aspectos sociais e ambientais (YOUNG, 2015).

A economia verde pode ser entendida ainda no contexto de que o crescimento econômico pode ocorrer com base no capital natural, mudando a direção dos modelos de desenvolvimento econômico para setores e tecnologias limpas que podem aos poucos ir substituindo as atividades e tecnologias sujas (MOTTA, 2011).

A OCDE adota a premissa de que a economia verde pode ser sinônimo de crescimento verde, e parte do entendimento de que venha a fomentar o crescimento e desenvolvimento econômico, assegurando de forma simultânea que os recursos naturais continuem a oferecer os recursos e serviços ambientais dos quais o crescimento econômico e social são dependentes (OCDE, 2011). GOUVELLO (2010) complementa dizendo que economia verde tem a ver diretamente com mudanças climáticas, com baixa emissão de carbono, eficiência energética, energia renovável, etc. Todavia, ambas as definições podem ser conceituadas como complementares e compartilham da mesma premissa teórica básica, a de preservar e conservar os recursos naturais (CEPAL, 2012).

Inicialmente adotada como uma ferramenta para enfrentar a crise financeira e econômica, a economia verde tornou-se uma estratégia extensamente aprovada na União Europeia e organizações internacionais no sentido de ser uma orientação de transição para uma sociedade mais justa que vive em um ambiente melhor (SPECK; ZOBOLI, 2017).

Em 2015, a comunidade internacional investiu em um novo pacto global para o desenvolvimento, acordo este que ficou conhecido como Agenda 2030 e os Objetivos do Desenvolvimento Sustentável (ODS). Dentro do cerne dos conceitos desse novo pacto, está a preocupação em por fim à pobreza e proteger o meio ambiente, mudando a forma de se produzir e consumir. Nesse sentido, a necessidade preeminente de desenvolver uma nova forma de trabalho, que pode ser denominada "empregos verdes" (O'RYAN e SCHAPER, 2017).

Existem dois grandes conjuntos de políticas que constituem os elementos essenciais para que se tenha a implementação de uma economia verde: o primeiro grupo reforça a ideia de reciprocidade entre o crescimento econômico e a conservação do capital natural e, segundo, o desenvolvimento de incentivos para impulsionar o uso eficiente dos recursos naturais (OCDE, 2011).

A economia verde é vista como uma possibilidade de dinamizar os efeitos, composição e tecnologia para conciliar crescimento econômico com qualidade ambiental e inclusão social, sendo este último o grande diferencial. Assim, como no conceito de desenvolvimento sustentável, o modelo da economia verde não oferece resposta para a preocupação da economia ecológica em definir uma escala sustentável, ou seja, definir limites de crescimento para torná-lo compatível com os limites biofísicos dados e, dessa forma, postergar a possibilidade de catástrofes ambientais (ALMEIDA, 2012).

A economia verde tem a proposta de assegurar que os bens naturais continuem a oferecer os recursos e serviços ambientais, os quais o nosso bem-estar social depende, fomentando o crescimento e desenvolvimento econômico (SELA, 2012). A adoção da economia verde nas economias pode ser capaz, inclusive, de dirimir os empregos informais, pois atua também com conceitos de inovação e, assim, pode gerar novas oportunidades para as sociedades (SMIT; MUSANGO, 2015).

O Programa das Nações Unidas para o Meio Ambiente (Pnuma) adverte quanto ao fato de que o conceito de economia verde não deve ser visto como substituto ao conceito de desenvolvimento sustentável, mas que a economia verde pode ser um instrumento para se alcançar o desenvolvimento sustentável (PNUMA, 2011). 
Assim, entende-se que o desenvolvimento sustentável é sistêmico, enquanto que a economia verde é um acréscimo marginal de alguns setores ou atividades. Pode-se resumir a economia verde à atividade da moda, como: painéis fotovoltaicos, parques nacionais remotos, pontos de reciclagem de lixo, entre outros. Nesse contexto, deve-se tomar cuidado para que a economia verde não acabe se tornando mera lavagem verde cosmética, o greenwashing (SAWYER, 2011).

A real economia verde, não a maquiagem sintetizada no greenwashing, permite uma visão que rompe com o paradigma de que os danos ambientais causados pelo processo produtivo e de consumo constituem um preço necessário para que se garanta o aumento da atividade econômica. De forma contrária, a economia verde propõe trazer benefícios positivos na geração de emprego e renda no curto e longo prazo, pois as atividades verdes tendem a ser mais intensivas em mão de obra e em produtos com maior conteúdo de inovação (YOUNG, 2015).

A partir do contexto da economia verde surge também o conceito de "emprego verde". Muçouçah (2009) define os "empregos verdes" como aqueles que contribuem substancialmente para preservar ou recuperar a qualidade ambiental. Podem ser definidos ainda como sendo uma combinação do tradicional ambiente da ciência com os campos da engenharia, juntamente com um olhar para novos regulamentos de modo a propiciar um futuro sustentável (DEITCHE, 2010).

Dessa forma, os "empregos verdes" podem ser criados em todos os setores e empresas, assim como em áreas urbanas e rurais, incluindo ocupações de trabalho manual até aqueles que demandam alta qualificação (BONELLI; LAZZARESCHI, 2015).

Caruso (2010) comenta que "emprego verde" é aquele que ajuda a preservar e restaurar o meio ambiente, a proteger os ecossistemas e as biodiversidades, a reduzir o consumo de energia, materiais e água, descarbonizar a economia e evitar a geração de resíduos e de poluição. Pela óptica da oferta, os "empregos verdes" podem ser entendidos como aqueles empregos que reduzem o impacto ambiental das empresas e dos setores econômicos a índices sustentáveis (RAMOS, 2016).

Em 2008, diversas instituições internacionais, entre elas a Organização Internacional do Trabalho (OIT) e o Programa das Nações Unidas para o Meio Ambiente (Pnuma), lançaram o estudo Green jobs: towards a decent work in a sustainable, low-carbon world, cujo objetivo foi de apresentar e destacar a possibilidade de impacto dos "empregos verdes" na economia (MONTEIRO et al., 2010).

Os "empregos verdes" ganharam destaque em economias e sociedades mais sustentáveis, capazes de preservarem o meio ambiente para as atuais e futuras gerações, garantindo maior equidade e inclusão das pessoas e países. Eles podem ser encontrados em um amplo rol de atividades como, por exemplo, fornecimento de energia, reciclagem, atividades agrícolas, construção civil e transportes (OIT, 2008).

Em alguns países, como, por exemplo, a China e Espanha, os investimentos nos setores de produção de energia solar e eólica são práticas bem-sucedidas de criação de "empregos verdes". No Brasil, potencial semelhante consiste nas atividades ligadas à bioenergia e programas de reciclagem (SANCHEZ; PORSCHEN, 2009).

Tomando como base o atual cenário de taxas elevadas de desemprego no Brasil, onde a taxa de desocupação apresenta aumento passando de 8,5\% em 2015 para 11,5\% em 2016, os meios tradicionais de subsídio para essa massa da população não serão suficientes e tenderão a agravar ainda mais a situação fiscal dos estados. Nesse sentido, uma saída pode ser o uso de mão de obra em atividades que façam o aproveitamento de desperdícios e de conservação do meio ambiente, ou seja, os "empregos verdes" podem ser uma alternativa para reduzir o nível de pessoas desocupadas no País (IBGE, 2017; DELAZARO; BARBIERI, 1994).

Como exemplo de uso dos "empregos verdes" como instrumento alternativo de potencial para a questão do desemprego associado ao meio ambiente, o Pnuma lançou, em 2008, em meio à eclosão da crise financeira mundial, a "Iniciativa Economia Verde", cujo objetivo era o de mobilizar e reorientar a economia global para investimentos em tecnologias limpas e infraestrutura natural, sendo então ferramentas para o crescimento associado ao combate às mudanças climáticas (ALMEIDA, 2012). 
Nesse sentido, com a necessidade dos municípios e demais esferas administrativas implementarem a Política Nacional de Resíduos Sólidos (PNRS), temos também a oportunidade de novas perspectivas para a geração de "empregos verdes" (MUÇOUÇAH, 2010). Iniciativas como, por exemplo, a redução do imposto de produtos industrializados (IPI) para eletrodomésticos da linha branca (que poluem menos), a inspeção veicular para controle de emissões e a regularização fundiária de propriedades rurais na Amazônia podem desenvolver os "empregos verdes" na economia do País (RAMOS, 2016).

Simas e Pacca (2013) descrevem que a transição da produção de energias fósseis para energias renováveis, como, por exemplo, a energia eólica, que possui a capacidade de gerar mais empregos para as localidades, pode, nesse caso, fomentar a geração de "empregos verdes".

Dentro do cerne de que a economia verde bem como o "emprego verde" são instrumentos de elevadas participações na busca do desenvolvimento sustentável, entende-se que a mensuração atual dos níveis de "empregos verdes" e daqueles com potencial de esverdeamentos é fundamental. Assim, este artigo tem como foco realizar um estudo para mensurar o "emprego verde" na região do Pantanal brasileiro.

Sua relevância consiste na mensuração do nível de atividades que possuam algum grau de preocupação com o meio ambiente no Pantanal, pois se trata de um dos biomas mais preservados no Brasil.

Em função do reconhecimento do Pantanal como patrimônio natural mundial e reserva da biosfera pela UNESCO, tem-se a preocupação com a manutenção e conservação do meio ambiente na região e, em paralelo, com a possibilidade de geração de emprego e renda para aqueles que residem no local.

De forma objetiva, pretendeu-se descrever quais atividades podem ser consideradas como "emprego verde" e aquelas de potencial de esverdeamento e, a partir dessa definição, realizar uma mensuração do "emprego verde" nos municípios pertencentes ao Pantanal. A busca pela compreensão de como as atividades produtivas exercem influência nesse bioma e sobre a própria sociedade é crucial, pois por meio desse conhecimento poder-se-á desenvolver políticas públicas que promovam o uso consciente dos recursos naturais do Pantanal, concomitante ao desenvolvimento social e econômico para as futuras gerações.

\section{PROCEDIMENTOS METODOLÓGICOS}

O objetivo geral deste trabalho foi mensurar o nível de "emprego verde" na região do Pantanal brasileiro, que ocupa $38,21 \%$ da área da bacia do Alto Paraguai no Brasil, perfazendo um total de 138.183 km2. O Pantanal está inserido nos estados de Mato Grosso (MT) e Mato Grosso do Sul (MS), abrangendo os seguintes municípios: Barão de Melgaço, Itiquira, Lambari d'Oeste, Nossa Senhora do Livramento, Poconé e Santo Antônio de Leverger no estado de MT; Aquidauana, Bodoquena, Corumbá, Coxim, Ladário, Miranda, Sonora, Porto Murtinho e Rio Verde de Mato Grosso no estado de MS, sendo Corumbá (MS) e Barão de Melgaço (MT) as cidades que possuem a maior área do Pantanal em seus respectivos territórios (SILVA; ABDON,1998).

No estado de Mato Grosso, os municípios pertencentes à região do Pantanal possuíam em 2010, ano do último censo, 86.351 habitantes, e em Mato Grosso do Sul, 283.768 habitantes, totalizando a população da região em 370.119 habitantes (IBGE, 2010).

Os dados sobre o "emprego verde" foram extraídos da Relação Anual de Informação Social (Rais) do Ministério do Trabalho (MT). A série histórica definida considera os anos de 2002 a 2015, a partir dos seguintes critérios: i) em função da nova metodologia do MT a respeito da Classificação Nacional de Atividades Econômicas (Cnae), adotada em 2002; ii) por ser o período mais recente de níveis de atividade econômica e social. Para subsidiar o processo da pesquisa foram utilizados os métodos estatístico, histórico e comparativo.

Bakker e Young (2011) afirmam que já foram utilizados três métodos para classificar os "empregos verdes", a saber: i) a Classificação de Atividades de Proteção e Despesas Ambientais (Cepa), elaborada pelo Escritório de Estatística da União Europeia (Eurostat); ii) a classificação realizada pela Organização 
Internacional do Trabalho (OIT), do potencial de "empregos verdes" no Brasil; iii) a seleção de atividades verdes do Sistema de Classificação da Indústria Norte Americana (NAICS), elaborada pelo Escritório Estatístico do Trabalho (BLS).

Dessa forma, entende-se que podem existir duas bases para a classificação do "emprego verde": uma setorial, partindo do princípio de haver setores que promovem a preservação e conservação ambiental, e a segunda base, uma abordagem ocupacional, com atividades que são desempenhadas com o objetivo de preservar e conservar os recursos naturais (NONATO; MACIENTE, 2012).

Vale ressaltar que, diante da metodologia empregada, o estudo pode apresentar conclusões parciais, visto que existe a possibilidade de se classificar uma atividade como "emprego verde", em função das suas caraterísticas, mas, em função da forma de produção e comercialização, essas atividades degradam o meio ambiente. Assim, tem-se a limitação quanto a uma caracterização homogênea das atividades produtivas, permitindo haver essa possibilidade de falha.

Com base no método desenvolvido por Bakker e Young (2011), modelo Cepa, descrevem-se três grupos de separação da Classificação Nacional de Atividade Econômica (Cnae) para a mensuração do "emprego verde".

No Brasil, o procedimento estatístico da descrição das ocupações e atividades funciona a partir do sistema de Classificação Nacional de Atividades Econômicas (Cnae). O modelo Cnae foi adotado de forma oficial no País em 1994 (versão Cnae 1.0) e passou por uma revisão em 2007, dando origem ao Cnae 2.0, para se adaptar ao padrão da Classificação Internacional de Atividades Econômicas (Ciae/ ONU). Esse modelo é utilizado na produção e disseminação de informações por tipo de atividade econômica nas estatísticas econômicas e socioeconômicas. A Cnae 2.0 apresenta cinco níveis de agregação de informações: seção, divisão, grupo, classe e subclasse. No trabalho, adotamos o nível de grupo que possui ao todo 285 categorias de atividades econômicas (IBGE, 2007).

A partir disso, no Quadro 1 apresentam-se os grupos de atividades em se tratando de "empregos verdes" e, também, das atividades que podem participar do processo de esverdeamento da cadeia produtiva. A classificação da Cnae utilizada foi a 2.0 grupo.

Quadro 1 - Grupos de atividades econômicas para geração de "emprego verde".

\begin{tabular}{ll}
\hline \multicolumn{1}{c}{ Grupo } & \multicolumn{1}{c}{ Descrição } \\
\hline Empregos Verdes & $\begin{array}{l}\text { Atividades diretamente relacionadas à } \\
\text { preservação ambiental e que se referem a } \\
\text { despesas de mitigação e proteção ao meio } \\
\text { ambiente. }\end{array}$ \\
Atividades verdes com potencial de \\
esverdeamento da economia, gerando \\
"empregos verdes" para alguns casos, \\
apenas. \\
Atividades sujas que dependem de inovações \\
intrassetoriais para que o processo produtivo \\
práticas verdes
\end{tabular}

Fonte: Adaptado de Bakker e Young (2011).

Em função da região do Pantanal brasileiro ser reconhecida como destino turístico e receber fluxo contínuo de pessoas e, por entender que as atividades ligadas ao turismo geram externalidades ao meio ambiente, adotamos como sendo o quarto grupo as atividades do turismo na região. Nesse caso, as atividades do turismo são consideradas atividades cujos impactos ambientais podem ser significativos e dependem da capacidade de gestão ambiental. 
A escolha desse método foi feita para identificar as atividades diretamente relacionadas à preservação e conservação do meio ambiente, as atividades que possuem potencial para esse fim, e aquelas que necessitam de uma gestão com viés ambiental para continuarem a existir.

\section{RESULTADOS E DISCUSSÃO}

A região compreendida como Pantanal e os respectivos municípios pertencentes apresentam uma taxa média de crescimento populacional de 20\% entre os anos censitários de 1991 e 2010, passando de 308.921 em 1991 para pouco mais de 370 mil habitantes em 2010, conforme dados extraídos do IBGE. Esse aumento contínuo no número de habitantes exerce externalidades sobre o meio ambiente, sejam externalidades positivas ou negativas. Por exemplo, com o aumento do número de habitantes, tem-se a necessidade de prover mais emprego e renda, aumentando os níveis de produção e consumo.

A economia dos municípios pertencentes ao Pantanal está em função de atividades ligadas ao agronegócio, de modo especial à produção de grãos e hortifrutigranjeiros e pecuária, em sua maioria. Em alguns municípios registram-se atividades ligadas ao turismo como, por exemplo, o ecoturismo.

A área do Pantanal no Brasil, um total de aproximadamente $140.000 \mathrm{~km} 2$, possui cerca de $30 \%$ de florestas naturais, distribuídas como florestas decíduas, semidecíduas e savanas florestadas. É público e notório que existe uma preocupação constante com a sustentabilidade dessas florestas, pois nos municípios pertencentes ao Pantanal o uso de madeiras é prática recorrente, em especial para a manutenção das propriedades no Pantanal (MATTOS et al., 2010).

Levando em consideração que o Pantanal é um bioma com diversas singularidades e tem registrado taxas de crescimento da população, bem como municípios com perfil de economia de atividades ligadas ao uso contínuo dos recursos naturais, torna-se de fundamental importância compreender o significado da economia verde e do "emprego verde" no contexto do bioma pantaneiro.

Os municípios objeto desta pesquisa somavam juntos 370.119 mil habitantes em 2010, sendo que no estado de Mato Grosso se encontram seis (6) municípios e em Mato Grosso do Sul nove (9). Esses quinze (15) municípios possuíam um estoque de 59.058 postos de trabalho formais, considerando o estoque em 31 de dezembro de 2015. Em 14 anos esses municípios registraram uma evolução do número de pessoas em atividade formal de 30\%, passando de 45.245 em 2002 para 59.058 em 2015, conforme os dados da Relação Anual de Informações Sociais (Rais), do Ministério do Trabalho (MT) (Tabela 1).

Tabela 1 - Vínculo ativo total, por ano, nos municípios da região do Pantanal (MS e MT).

\begin{tabular}{|c|c|c|c|c|c|c|c|c|c|c|c|c|c|c|c|}
\hline Ano & 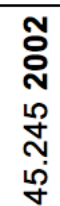 & 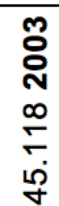 & 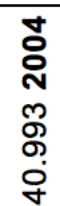 & 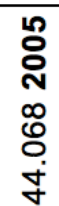 & 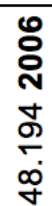 & 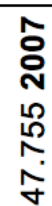 & 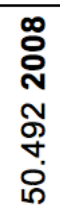 & 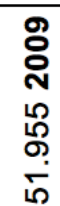 & $\begin{array}{l}0 \\
\text { 으 } \\
0 \\
0 \\
0 \\
0\end{array}$ & & & & & $\begin{array}{l}\text { N. } \\
\vdots \\
\infty \\
\infty \\
\infty \\
\infty\end{array}$ & $\begin{array}{l}\text { Lొ } \\
\text { న } \\
\infty \\
0 \\
0 \\
0\end{array}$ \\
\hline
\end{tabular}

Fonte: Elaboração própria, a partir de dados da Rais.

Os municípios do estado de Mato Grosso do Sul possuíam 46.065 postos de trabalho em 31 de dezembro de 2015 , representando $78 \%$ de todos os postos da região pantaneira, e os municípios do estado de Mato Grosso registram 12.993 postos, (22\%) do estoque no mesmo período.

Em se tratando do total das atividades que estão diretamente relacionadas à preservação ambiental, nos 15 municípios que contemplam a região do Pantanal, denominados aqui como "empregos verdes", perfazem um total de 2.522 postos de trabalho, o que corresponde a $4,27 \%$ do estoque em dezembro de 2015. No acumulado da série histórica (2002-2015), esse grupo detinha 4,13\% das ocupações de atividades formais, aproximadamente, 29.637 postos ocupados. Em 2006, ano em que os dados 
aparecem desagregados pela primeira vez pela Rais-MT para essa série histórica, tinha-se um saldo acumulado de 3.366 e, em 2015, com 2.522, registrando uma redução dos “empregos verdes" em $25 \%$.

Levando em consideração o saldo acumulado dos "empregos verdes" no Pantanal, 94\% destes pertencem à iniciativa privada e $6 \%$ referem-se ao setor público. Dessa forma, é possível dizer que, para essa região e no período de tempo determinado na pesquisa, o setor público possui pouca atuação no que tange à criação e manutenção de "empregos verdes".

Pelo fato de o estado de MS possuir maior número de municípios do que o MT pertencentes ao bioma pantaneiro, as localidades inseridas no Pantanal de Mato Grosso do Sul possuem juntas 1.894 postos de trabalhos de atividades diretamente relacionadas à preservação da qualidade ambiental, enquanto que os municípios mato-grossenses possuem 628 postos de trabalho. Em relação às atividades limpas com potencial de esverdeamento, no Pantanal de MS tem-se 14.375 postos ligados a essas atividades e 3.643 em Mato Grosso. As atividades cujos impactos ambientais podem ser significativos e dependem da capacidade de gestão ambiental somam 17.393 postos no MS e 6.464 no MT. O número de trabalhadores ligados diretamente ao turismo em MS é de 1.846 e em MT, 624 trabalhadores (Tabela 2).

Tabela 2 - Total de vínculos ativos, por grupo de atividades, por estado, em 2015.

\begin{tabular}{lcc}
\hline \multicolumn{1}{c}{ Grupo de Atividades } & MS & MT \\
\hline $\begin{array}{l}\text { Atividades diretamente relacionadas à preservação da qualidade } \\
\text { ambiental }\end{array}$ & 1894 & 628 \\
Atividades limpas com potencial de esverdeamento & 14.375 & 3.643 \\
$\begin{array}{l}\text { Atividades cujos impactos ambientais podem ser significativos e } \\
\text { dependem da capacidade de gestão ambiental }\end{array}$ & 17.393 & 6.464 \\
Atividades diretas do turismo & 1.846 & 625 \\
Total & 35.508 & 11.360 \\
\hline
\end{tabular}

Fonte: Elaboração própria, a partir de dados da Rais.

Nos municípios que compõem a região do Pantanal registrou-se uma diminuição de $25 \%$ de pessoas trabalhando nas atividades diretamente relacionadas à preservação da qualidade ambiental, entre o início da série histórica (aqui considerado 2006, pois 2002 não há desagregação por atividade) e o último ano (2015). O número de trabalhadores nas atividades limpas com potencial de esverdeamento aumentou $24 \%$, e nas atividades cujos impactos ambientais podem ser significativos e dependem da capacidade de gestão ambiental, $18 \%$ no mesmo período.

Com aumento de 51\%, as atividades diretas ligadas ao turismo apresentam maior evolução (Tabela 3).

Tabela 3 - Total de vínculos ativos, por grupo de atividades, em 2006 e em 2015.

\begin{tabular}{lccc}
\hline \multicolumn{1}{c}{ Grupo de Atividades } & 2006 & 2015 & Variação \\
\hline Atividades diretamente relacionadas à preservação da & 3.366 & 2.522 & $-25 \%$ \\
qualidade ambiental & 14.487 & 18.018 & $24 \%$ \\
Atividades limpas com potencial de esverdeamento & 20.144 & 23.857 & $18 \%$ \\
$\begin{array}{l}\text { Atividades cujos impactos ambientais podem ser significativos e } \\
\text { dependem da capacidade de gestão ambiental }\end{array}$ & 1.635 & 2.471 & $51 \%$ \\
\hline Atividades diretas do turismo & & \\
\hline
\end{tabular}


No grupo dos "empregos verdes", as ocupações de atividades que apresentaram maior destaque entre os anos de 2006 e 2015 foram: coleta de resíduos com aumento de 99\%; tratamento e disposição de resíduos com 460\% de aumento, passando de cinco postos de atividades em 2006 para 28 em 2015; os postos de atividades de captação, tratamento e distribuição de água apresentaram aumento maior que $100 \%$, passando de cinco postos para 28 ; e atividade de pesquisa e desenvolvimento experimental em ciências físicas e naturais tendo mais que dobrado, passando de 4 postos de trabalho para 164 em 2015. As atividades ligadas ao patrimônio cultural e ambiental registraram evolução maior que $100 \%$, saltando de apenas um posto de trabalho em 2006 para 33 em 2015. Por outro lado, as ocupações relacionadas à fabricação de biocombustíveis caíram 55\%, passando de 1.336 postos em 2006 para 595 em 2015, e esgoto e atividades relacionadas perderam $33 \%$ de postos de trabalho no mesmo período de comparação.

Em se tratando das ocupações de atividades limpas com potencial de esverdeamento, o destaque fica por conta da aquicultura, passando de 29 postos em 2006 para 375 em 2015. As atividades do setor público, em específico de ensino, também registram aumento na comparação entre os períodos, bem como as atividades de recuperação e manutenção de equipamentos eletrodomésticos e de informática. Os destaques negativos derivam das ocupações de serviços coletivos prestados pela administração pública e serviços de assistência social sem alojamento.

$\mathrm{Na}$ especificação das atividades cujos impactos ambientais podem ser significativos e dependem da capacidade de gestão ambiental, as maiores evoluções de postos de trabalho são das atividades de laticínios (308\%), extração de outros minerais não metálicos (206\%), extração de minerais metálicos não ferrosos (158\%), transporte rodoviário de carga (156\%), produção florestal - florestas plantadas (90\%) e pecuária (25\%) entre 2006 e 2015 . Em compensação, o número de postos de trabalho na produção de lavouras permanentes diminuiu 99\%, passando de 1.436 em 2006 para 21 em 2015.

As atividades diretas do turismo de hotelaria e serviços de alimentação tiveram aumento de $35 \%$ e $99 \%$, respectivamente. Nesse extrato de grupo, o único registro de redução de postos de trabalho por ocupação de atividade foi de agência de viagens e operadores turísticos, passando de 176 em 2006 para 125 em 2015.

Ao se desagregar os dados por estado, observa-se que os municípios do estado de MS foram os que aumentaram o número de postos de trabalho em atividades diretamente relacionadas à preservação da qualidade ambiental (40\%), enquanto que os municípios de MT registraram uma queda de $70 \%$.

Contudo, nesse nível de especificidade de informação, destacam-se as atividades diretas do turismo, grupo onde as atividades podem gerar impactos ambientais significativos e dependem da capacidade de gestão ambiental, em especial em MT, tendo uma variação de $113 \%$ (Tabela 4).

Tabela 4 - Total de vínculos ativos, por grupo de atividades, por estado (2006 e 2015).

\begin{tabular}{|c|c|c|c|c|c|c|}
\hline Ano & \multicolumn{2}{|c|}{2006} & \multicolumn{2}{|c|}{2015} & \multicolumn{2}{|c|}{ Variação } \\
\hline Grupo de Atividades & MS & MT & MS & MT & MS & MT \\
\hline $\begin{array}{l}\text { Atividades diretamente relacionadas à } \\
\text { preservação da qualidade ambiental }\end{array}$ & 1.197 & 1.677 & 1.681 & 500 & $40 \%$ & $-70 \%$ \\
\hline $\begin{array}{l}\text { Atividades limpas com potencial de } \\
\text { esverdeamento }\end{array}$ & 12.399 & 1.800 & 14.396 & 3.424 & $16 \%$ & $90 \%$ \\
\hline $\begin{array}{l}\text { Atividades cujos impactos ambientais podem ser } \\
\text { significativos e dependem da capacidade de } \\
\text { gestão ambiental }\end{array}$ & 15.290 & 5.260 & 17.532 & 6.325 & $15 \%$ & $20 \%$ \\
\hline Atividades diretas do turismo & 1.335 & 288 & 1.823 & 614 & $37 \%$ & $113 \%$ \\
\hline
\end{tabular}

Fonte: Elaboração própria, a partir de dados da Rais.

A partir da variação relativa ano a ano, mensurou-se a taxa média de crescimento em termos porcentuais dos grupos de atividades e, nesse caso, as atividades diretamente relacionadas à preservação da qualidade ambiental apresentaram queda de $-2 \%$, enquanto que as atividades cujos 
impactos ambientais podem ser significativos e dependem da capacidade de gestão ambiental, que vão desde a produção de lavouras e agropecuária à extração mineral e fabricação de produtos industriais, cresceram $2 \%$. Atividades limpas com potencial de esverdeamento tiveram aumento médio de $3 \%$, e as atividades diretas do turismo $5 \%$.

Por estado, a média de postos de trabalho relacionados à preservação da qualidade ambiental em MS (4\%) é melhor do que no estado de MT (-11\%). Atividades limpas com potencial de esverdeamento registram $2 \%$ em MS e $9 \%$ em MT. As atividades cujos impactos ambientais podem ser significativos e dependem da capacidade de gestão ambiental representam $2 \%$ para os dois estados. As ocupações a partir das atividades do turismo apresentam média de $4 \%$ em Mato Grosso do Sul e $9 \%$ em Mato Grosso.

\section{CONSIDERAÇÕES FINAIS}

Os 15 municípios que pertencem ao bioma Pantanal registraram, em 2015, um estoque de 59.058 postos de trabalho formais, considerando o estoque em 31 de dezembro do respectivo ano. Entre 2002 e 2015 , os municípios pantaneiros tiveram um aumento de $30 \%$ no número de pessoas em atividades empregatícias formais. Nesse caso, os municípios sul-mato-grossenses possuíam $78 \%$ do total em 2015 , e os municípios mato-grossenses $22 \%$.

Em geral, nota-se uma queda de $25 \%$ nos postos de trabalho ligados a atividades diretamente relacionadas à preservação da qualidade ambiental, embora se tenha um aumento de $24 \%$ no número de postos de trabalho nas atividades limpas com potencial de esverdeamento. As atividades cujos impactos ambientais podem ser significativos e dependem da capacidade de gestão ambiental apresentam crescimento de $18 \%$, e as atividades diretas do turismo $51 \%$. Destaca-se que neste estudo o turismo é considerado como atividade de impactos ambientais e que dependem da capacidade de gestão ambiental.

Os municípios pertencentes ao estado de MS obtiveram aumento de $40 \%$ nos postos de trabalho em atividades de preservação da qualidade ambiental, ou seja, de "empregos verdes", enquanto que em Mato Grosso, nesse mesmo grupo de atividades, houve uma redução de $70 \%$.

Embora seja um resultado preocupante, os municípios de MT, do bioma pantaneiro, registraram maior evolução de postos de trabalho nas atividades limpas com potencial de esverdeamento (90\%), enquanto que em MS foi de $16 \%$. Nas atividades cujos impactos ambientais podem ser significativos e dependem da capacidade de gestão ambiental também houve aumento no número de pessoas trabalhando, sendo de $15 \%$ em MS e $20 \%$ em MT.

Assim, pode-se concluir que houve redução de "empregos verdes" na região do Pantanal entre 2002 e 2015. Essa redução foi impactada pelos municípios de Mato Grosso que apresentaram queda de $70 \%$, enquanto que em Mato Grosso do Sul houve aumento de 40\%, mas insuficiente para reverter o cenário de queda dos "empregos verdes" na região pantaneira.

Apesar desse resultado, os municípios pantaneiros de Mato Grosso apresentaram melhores resultados em atividades limpas com potencial de esverdeamento, contudo, o número de pessoas trabalhando nas atividades cujos impactos ambientais podem ser significativos e dependem da capacidade de gestão ambiental também aumentou.

\section{REFERÊNCIAS}

ALMEIDA, L. T. Economia verde: a reiteração de ideias à espera de ações. Estudos avançados. v. 26, p. 93-106, 2012.

BAKKER, L. B.; YOUNG, C. E. F. Caracterização do emprego verde no Brasil. In: ENCONTRO DA SOCIEDADE BRASILEIRA DE ECONOMIA ECOLÓGICA, 9., 2011, Brasília. Anais... Brasília, 2011. 
BONELLI, V. V.; LAZZARESCHI, N. Empregos verdes e sustentabilidade: tendências e desafios no Brasil. Revista de Ciências Sociais. v. 46, p. 221-242, 2015.

CARUSO, L. A. C. Skills for green jobs in Brazil: unedited background country study. Geneva: OIT-Skills and Employability Department, 2010.

CEPAL. Cambio estructural para la igualdad: una visión integrada del desarrollo. 2012.

DEITCHE, S. M. Green collar jobs: environmental careers for the 21st century. Santa Barbara (CA-USA): PRAEGER, 2010 .

DELAZARO, W.; BARBIERI, J. C. Geração de Empregos e preservação do meio ambiente: o grande desafio. Revista de Administração de Empresas (RAE). v. 34, p. 73-39, 1994.

GOUVELLO, C. Brazil Low-carbon Country Case Study. Washington DC: The World Bank Group, 2010.

INSTITUTO BRASILEIRO DE GEOGRAFIA E ESTATÍSTICA. Introdução à Classificação Nacional de Atividades Econômicas - Cnae - versão 2.0. Rio de Janeiro: IBGE, 2007.

INSTITUTO BRASILEIRO DE GEOGRAFIA E ESTATÍsTICA. Censo 2010. Rio de Janeiro: IBGE, 2010.

INSTITUTO BRASILEIRO DE GEOGRAFIA E ESTATÍSTICA. Pesquisa Mensal de Emprego - PME. Rio de Janeiro: IBGE, 2017.

MATTOS, P. P. de. et al. Manejo sustentável de florestas naturais da região do Pantanal bras. Ciência florestal. v. 20, p. 321-333, 2010.

MONTEIRO, M. I.; CORRÊA FILHO, H. R.; SIQUEIRA, C. E. Green Jobs, green economy: ampliando as possibilidades de desenvolvimento sustentável. In: VILARTA, R.; GUTIERREZ, G. L.; MONTEIRO, M. I. (Org.). Qualidade de vida: evolução dos conceitos e práticas no século XXI. Campinas: Ipes Editorial; 2010. p. 169-206.

MOTTA, R. S. Valoração e precificação dos recursos ambientais para uma economia verde. Revista Política Ambiental. v. 1, n. 8, p.179-190, 2011.

MUÇOUÇAH, P. S. Empregos Verdes no Brasil: quantos são, onde estão e como evoluirão nos próximos anos. Organização Internacional do Trabalho. Brasil: OIT, 2009.

A política nacional de resíduos sólidos e a geração de empregos verdes. Bahia Análise \& Dados. v. 20, p. 349-360, 2010.

NONATO, F. J. A. P.; MACIENTE, A. N. A identificação dos empregos verdes, ou com potencial verde, sob as óticas ocupacional e setorial. Radar Ipea. Rio de Janeiro, v. 1, n. 23, p. 1-10, 2012.

ORGANIZAÇÃO DAS NAÇÕES UNIDAS. The Future We Want: Outcome of the United Nations Conference on Sustainable Development. Rio de Janeiro, Brazil, June 20-22, 2012.

ORGANIZAÇÃO DAS NAÇÕES UNIDAS. Brundtland, G. H. et al. (1987). Nosso futuro comum. Comissão Mundial sobre Meio Ambiente e Desenvolvimento. Nova York: ONU.

ORGANIZAÇÃO DAS NAÇÕES UNIDAS PARA A EDUCAÇÃO, A CIÊNCIA E A CULTURA. Convention concerning the protection of the world cultural and natural heritage. Cairns: Austrália. 2000.

ORGANIZAÇÃO INTERNACIONAL DO TRABALHO. Empregos verdes: trabalho decente em um mundo sustentável e com baixas emissões de carbono. 2008.

ORGANIZAÇÃO PARA A COOPERAÇÃO E DESENVOLVIMENTO ECONÔMICO. A caminho do crescimento verde: um sumário para os decisores políticos. 2011.

O’RYAN, R.; SCHAPER, M. Economía verde y crecimiento verde. In: ROVIRA, S.; PATINO, J.; SCHAPER, M. (Org.). Ecoinnovación y producción verde: una revisón sobre las políticas de América Latina y el Caribe. Santiago: CEPAL, 2017. p. 13-17. 
PMDBBS. Projeto de Monitoramento do Desmatamento dos Biomas Brasileiros por Satélite. IBAMA: Brasília, 2011.

PROGRAMA DAS NAÇÕES UNIDAS PARA O MEIO AMBIENTE. Caminhos para o Desenvolvimento Sustentável e a Erradicação da Pobreza. 2011.

RAMOS, C. Desenvolvimento econômico sustentável: tendências e desafios na promoção dos empregos verdes no Brasil. Textos e debates. n. 30, p. 23-38, jul./dez. 2016.

SACHS, I. Desenvolvimento sustentável - desafio do século XXI. Ambiente \& Sociedade. São Paulo, v. 8, n. 2, p. 214-215, 2004.

SANCHEZ, A. B.; POSCHEN, P. The social and decente work dimensions of a new a greement on climate change. Genebra: ILO/Policy Integration Department, 2009.

SAWYER, D. Economia verde e/ou desenvolvimento sustentável? Revista Política Ambiental. v. 1, n. 8, p. 36-42, 2011.

SELA - Sistema Económico Latinoamericano y del Caribe. La visión de la economía verde en América Latina y el Caribe. 2012.

SHMELEV, S. Green economy reader: lectures in ecological economics and sustainability. Oxford, 2017.

SILVA, J. S. V.; ABDON, M. M. Delimitação do Pantanal brasileiro e suas sub-regiões. Pesquisa Agropecuária Brasileira. Brasília, v. 33, Número Especial, p. 1703-1711, 1998.

SIMAS, M.; PACCA, S. Energia eólica, geração de empregos e desenvolvimento sustentável. Estudos Avançados. v. 27, n. 77, p. $98-116,2013$.

SMIT, S.; MUSSANGO, J. Towards connecting green economy with informal economy in South Africa: a review and way forward. Ecological Economics. v. 116, p. 154-159, 2015.

SPEAK, S.; ZOBOLI, R. The Green Economy in Europe. In: Search for a Successful Transition. SHMELEV, S. (Org.). Green economy reader: lectures in ecological economics and sustainability. Oxford. 2017. p. 141-160.

WENCESLAU, J.; ANTEZANA, N. L.; CALMON, P. P. Políticas da terra: existe um novo discurso ambiental pós-Rio+20? Cadernos Ebape. v. 10, n. 3, p. 584-604, 2012.

YOUNG, C. E. F. Perspectivas e desafios para uma estratégia de crescimento verde no Brasil. Pontes. v. 11, p. 1115, 2015. 